\title{
Potential Dietary Outcomes of Changing Relative Prices of Healthy and Less Healthy Foods: The Case of Ready-to-Eat Breakfast Cereals
}

\begin{abstract}
Many prevalent and costly health disorders in the U.S. can be attributed in part to poor diets, overconsumption of calories, and physical inactivity. Taxing less healthy foods and subsidizing healthy foods as a strategy to improve diet and health has attracted growing interest among policy makers and researchers. We test this strategy by using national household purchase data to estimate a censored, price and expenditure endogenous demand system for 12 food groups that are commonly consumed at breakfast: low- and high-nutrition ready-to-eat breakfast cereals, eggs, breads, hot cereals, breakfast bars, juice, whole and reduced-fat milk, yogurt, meats, and coffee. The estimated demand elasticities are applied to nationally representative food intake data to simulate - under the assumption of perfectly price elastic supply - the potential dietary improvement from taxing low-nutrition and subsidizing high-nutrition ready-to-eat breakfast cereals. We find that the demand for both types of cereals is own-price inelastic, suggesting that consumers are not likely to make large shifts in consumption of cereals if the price changes. Thus only limited dietary improvement can be expected from taxes and subsidies. Furthermore, when the healthfulness of breakfast foods is evaluated using a comprehensive list of nutrients and food components, a price intervention strategy may result in unintended, adverse impacts. Our simulation results suggest that the hypothetical price intervention actually increases the calorie content of foods consumed at breakfast.
\end{abstract}

Keywords: food demand, subsidy and taxation, breakfast cereals, pricing strategy, dietary outcomes

Acknowledgements. The authors thank Mario Mazzocchi and three anonymous referees for their helpful comments and suggestions. The views in this paper are those of the authors and do not necessarily reflect the views or policies of the U.S. Department of Agriculture. 


\section{Introduction}

In the U.S. there are several highly prevalent health disorders, which can be attributed in part to poor diets, overconsumption of calories, and physical inactivity (CDC, 2015; Ogden et al., 2014; USDHHS/USDA, 2015). These disorders, such as obesity, hypertension, and cardiovascular disease impose considerable economic costs through increased health care expenditure

and lost productivity (Cawley and Meyerhoefer, 2012; Finkelstein et al., 2009). Consequently, dietary improvement has been a long-term policy goal of the U.S. Federal Government. Federal policy prescriptions have included (1) providing healthy foods directly to individuals and increasing the resources available to households to buy food through an array of food and nutrition assistance programs administrated by the USDA (Oliveira, 2014), (2) increasing the information available to individuals about what constitutes a healthy diet (USDHHS/USDA, 2015), and (3) mandatory nutrition and menu labeling requirements enacted in 1994 and 2014 (FDA, 2015).

Under the premise that food prices are important determinants of consumers' food choices, policy makers and researchers have been interested in fiscal policies aimed at influencing the relative prices of foods via taxes or subsidies to promote healthier food choices. In 2008, the U.S. Congress authorized a pilot project to evaluate subsidizing the purchase of fruits, vegetables, or other healthful foods among individuals who participate in the Supplementary Nutrition Assistance Program (FNS/USDA, 2015). Using a random assignment design, a 30-percent rebate resulted in a 26-percent increase in fruit and vegetable consumption (Bartlett et al., 2014). Similarly, price intervention has been found to be effective in steering consumers toward a more healthful diet (Duffey et al., 2010; French et al., 2001; French et al., 2003; Thow et al., 2014) and relative prices of healthful and less healthful foods have been 
associated with changes in health conditions (Meyerhoefer and Leibtag, 2010; Powell et al., 2013; Rahkovsky and Gregory, 2013). On the other hand, other researchers found that taxes and subsidies have limited effect on food consumption, diet or health (Dharmasena and Capps, 2012; Dharmasena et al., 2014; Finkelstein et al., 2010; Fletcher et al., 2010; Kuchler et al., 2005; Lin et al., 2010; Lin et al., 2011; Mytton et al., 2012; Sharma et al., 2014; Tiffin et al., 2014; Zhen et al., 2010).

The findings that fiscal policy has limited effects on food consumption, diet or health are not surprising because many researchers find that the demand for food and beverages is price inelastic, especially when broadly defined food groups are specified in the demand system. In a review article Andreyeva et al. (2010) reported that the own-price elasticities for foods and beverages range between -0.27 and -0.81 . As stated by McCloskey (1982), the “ $\ldots$ first fundamental theorem of taxation: a tax has little effect on inelastic goods ...” (p. 309). However, the demand for broadly defined foods is less responsive to price changes than the demand for disaggregated foods because potential substitutions between closely related foods are omitted when they are aggregated into the same category. Further, the cross-price effects need to be incorporated into the analysis in order to examine the full effectiveness of fiscal policy on food consumption (Capacci et al., 2012; Cornelsen et al., 2014; Zhen et al., 2013). Clearly, more research on the effectiveness of fiscal policy on dietary improvement is needed (Thow et al., 2010). More recently, the 2015 Dietary Guidelines Advisory Committee (DGAC, 2015) concludes that “... Economic and pricing approaches, using incentives and disincentives should be explored to promote the purchase of healthier foods and beverages."

In a study evaluating the effectiveness of a supermarket shelf nutrition-information system, Rahkovsky et al. (2013) estimated a demand system of ready-to-eat (RTE) breakfast 
cereals, in which four categories of cereals were specified based on their nutritional profiles. In an extension of this work, Lin et al. (2014) used the estimated demand to simulate the dietary outcomes of the nutrition information system as well as a hypothetical fiscal policy of subsidizing more nutritious RTE cereals and taxing nutrition-poor RTE cereals. They found that both intervention strategies resulted in significantly increased sales of more nutritious RTE cereals at the expense of less nutritious RTE cereals, but the resulting dietary improvement was small. A major limitation of these studies is that foods and beverages that are closely related to RTE cereals consumption were omitted from the demand system. The omission of closely related foods may result in biased demand price elasticities, and the cross-price effects of omitted foods are absent in the simulation of dietary changes.

Our research objective was to investigate the dietary outcomes of implementing a hypothetical fiscal policy targeting ready-to-eat breakfast cereals (hereafter, RTE cereals), namely taxing low-nutrition and subsidizing high-nutrition RTE cereals. We used household purchase data from a national panel to estimate a demand system of 12 groups of foods and beverages that are commonly consumed at breakfast (hereafter, breakfast foods), including lowand high-nutrition ready-to-eat breakfast cereals, eggs, breads, hot cereals, breakfast bars, juice, whole and reduced-fat milk, yogurt, meats, and coffee. Because most households did not purchase all of the breakfast foods, and household characteristics influence both the quality of the foods chosen and total expenditure on breakfast foods, we specified a censored demand with endogenous prices and total breakfast food expenditure. We found that the demand for both types of cereals is own-price inelastic, suggesting that consumers are not likely to make large shifts in consumption of cereals if the price changes. Thus only limited dietary improvement can be expected from taxes and subsidies. Furthermore, when the healthfulness of breakfast foods is 
evaluated using a comprehensive list of nutrients and food components, a price intervention strategy may result in unintended, adverse impacts. Our simulation results suggest that the hypothetical price intervention actually increases the calorie content of foods consumed at breakfast.

Section 2 describes the data used in this study focusing on their unique roles in modeling and simulation analyses. Section 3 defines the empirical demand model and reports demand elasticity estimates. Section 4 explains the simulation method to analyze fiscal policy impacts on selected dietary quality measures and reports simulation results. Section 5 concludes.

\section{Data}

\subsection{Data Sources}

Two nationwide food purchase and consumption datasets are supplemented with a nutrition database to estimate the impact of fiscal policies that change the price of RTE cereals on dietary outcomes. We estimated demand for RTE cereals using household food purchase data from the 2006 Nielsen Homescan panel (Einav et al., 2008). Since the hypothetical fiscal policy studied here was to lower the price of nutrition-rich RTE cereals and raise the price of nutritionpoor RTE cereals, we needed to classify RTE cereals into two categories according to their nutritional profiles. In this study, we fitted a wide array of nutrient and food component data into the nutrition scoring algorithm developed for the Guiding Stars Program (Fischer et al., 2011) to classify RTE cereals into nutrition-rich and nutrition-poor cereals. Since the nutritional data required for this classification was not included in the Homescan data, we turned to the Nutrition Facts Panel data found in the Gladson data (Gladson, 2015). We attached the nutrition data from Gladson to the RTE cereals reported by Homescan participants by using the Uniform 
Product Code (UPC), which is available in both data sets. Finally, we applied the demand elasticity estimates to the dietary recall data found in the 2005-6 National Health and Nutrition Examination Survey (NHANES) (CDC/NCHS, 2009) to simulate policy changes.

\subsubsection{Nielsen Homescan Panel}

Nielsen maintains a national panel of households who record their grocery purchases from all retail outlets (including supermarkets, super centers, club warehouses, convenience stores, drug stores, health food stores, etc.) (Einav et al., 2008). Each household (approximately $40,000)$ in the full 2006 Homescan panel was supplied with a scanner device to report food and beverage purchases by scanning the Uniform Product Code (UPC) for packaged foods. This study used the subsample—Fresh Foods Panel $(\mathrm{n}=7,534)$. Households in this subsample were supplied with an additional code book to record both UPC and non-UPC items, such as unpacked produce, meats packaged by the store, and bakery products. After excluding six households with missing demographic data, there are 7,528 households included in our analysis. Each purchased item was recorded with the date, the quantity purchased, expenditure for that quantity, promotional information including whether or not the item was on sale or purchased with coupons, store type, and detailed product characteristics. In 2006, RTE cereal purchase data contain 4,162 unique UPCs. We represented the price paid for each purchased item as a unit value - the ratio of reported expenditures (net any promotional and sale discounts) to the reported quantities. In order to derive consistent prices for demand estimation, all quantities were measured on the basis of ready to serve. For example, frozen concentrated juice, frozen dough, and ground and instant coffee were converted to ready-to-serve weights or fluid ounces before they are added to their respective groups. 
Household purchase data are available more recently than 2006, but we used 2006 data because Americans' eating patterns shifted during the recession of 2007-2009 (Todd, 2014) and reverted back to the before-recession pattern in 2011-12 (Guthrie et al., 2016). Data from the NHANES indicate that the share of calories from home food sources (mainly grocery stores) trended downward from 82 percent in 1977-78 to 66 percent in 2005-06, but rose to 68 percent in 2007-08 and 71 percent in 2009-10, and then reverted back to 66 percent during 2011-12. Even though household purchase data after 2011 were available, the corresponding NHANES data needed for the simulation were not available to us when we began our study.

\subsubsection{Gladson}

Nielsen's Homescan data contain purchase related data but not nutrition data so that RTE cereals reported by the Homescan panel cannot be distinguished by their nutritional profile. Gladson collects nutrition data from the Nutrition Facts Panel for packaged foods, including RTE cereals (Gladson, 2015). The Uniform Product Codes (UPCs) are available in both Homescan and Gladson. We used the UPC codes to attach nutrition data from Gladson to RTE cereals in Homescan.

\subsubsection{National Health and Nutrition Examination Survey (NHANES)}

The U.S. Departments of Health and Human Services and Agriculture jointly conduct the nationally representative NHANES. Respondents reported their entire food intake over 2 nonconsecutive 24-hour periods (CDC/NCHS, 2009). Foods reported in NHANES are categorized into more than 7,000 unique food items, including 209 unique RTE cereals, with detailed descriptions. To monitor Americans' diets, USDA maintains nutrition databases for all foods 
reported in NHANES (ARS/USDA, 2015). NHANES survey has been implemented to monitor Americans' nutrition and health status. NHANES data are released every two years and we used the 2005-06 data to simulate the dietary outcomes of altering prices of RTE cereals. NHANES does not contain price data so they cannot be used for demand estimations.

\subsection{Data preparation}

In this study, the demand system for breakfast foods was specified with 12 food groups, including two types of RTE cereals (high- and low-nutrition cereals), milk (whole and reducedfat milk), yogurt, eggs, coffee, juice, breads, hot cereals, breakfast bars, and processed meats and vegetables (such as sausage, bacon, ham, or frozen potatoes, which are termed "meats" for convenience). We estimated the demand system using Homescan data and then applied the estimated demand to NHANES food and nutrient data to simulate the dietary outcomes of implementing several policy scenarios. Each food reported in NHANES has a detail description and the description was used to identify its corresponding food group in the demand system. Nutrient data were used to distinguish RTE cereals by their nutrition profile. NHANES food and nutrient intake data are ideal and have been used for simulating the dietary outcomes of dietary intervention strategies (e.g., Lin et al., 2011).

\subsubsection{Linking Homescan and Gladson to obtain nutrition data for cereals}

In order to classify the RTE cereals purchased by Homescan participants as high- and low-nutrition, we used the UPCs to match these RTE cereals to the same RTE cereals in Gladson. Among the 4,162 RTE cereals purchased by Homescan participants, 1,278 of them had matching UPCs in the Gladson database, accounting for 86 percent of the RTE cereal sales 
reported in the 2006 Homescan. An internet search netted the Nutrition Facts Panel data for an additional 45 RTE cereals. For the remaining cereals, we visually inspected the description and Nielsen's product dictionary groupings to assign a matched UPC (which have nutrient data from Gladson) to an unmatched UPC. In the end, there were 146 RTE cereals in Homescan that could not be assigned a UPC with nutrition data. Most of these RTE cereals were private label with only a brief description or bundled packages containing a variety of different RTE cereals. These RTE cereals accounted for negligible sales and were assigned as low-nutrition cereals.

\subsubsection{Applying Guiding Stars to identify low- and high-nutrition cereals}

Using the nutrition data from Gladson, we calculated the nutritional scores of RTE cereals by applying the nutrition scoring algorithm developed for the Guiding Stars Program (GSP) (Fischer et al., 2011). The GSP incorporates all nutrients with a scientific consensus of significant health promotion or an associated health risk. Nutrients with health promoting attributes (vitamins and minerals, fiber, and whole grains) receive positive scores and nutrients to limit (trans-fatty acids, saturated fatty acids, cholesterol, sodium, and sugars) receive negative scores $^{1}$. The GSP groups foods into two main categories- - those with positive overall nutritional scores are assigned a star rating (one to three stars) and those with negative scores are not assigned a star rating. In this study, the RTE cereals that received negative scores were classified as "low-nutrition" while we classified those with positive scores as "high-nutrition."

\section{Empirical Demand Model Specification and Results}

\footnotetext{
${ }^{1}$ The Nutrition Fact Panel contains most of but not all the nutrient and food component data specified in the Guiding Stars Program (GSP). For example, whole grain is not reported in the Nutrition Facts Panel and hence not incorporated in the calculation of nutrition scores using the GSP. However, dietary fiber is reported in the Nutrition Facts Panel and it is highly correlated with whole grains content. Fitting Nutrition Facts Panel data to the GSP algorithm does result in lower nutrition scores by missing data on whole grains.
} 
Homescan household grocery purchase data were used in this study to estimate demand elasticities for the 12 breakfast food groups. Since not all households purchased all of the 12 food groups, handling the zero purchases became a challenge in estimating the demand system. In addition, zero-purchase households had no expenditure to report, so there were missing prices which added another level of complexity to the model estimation. To solve for both the zero purchase problem and the missing price problem, we followed Dong et al. (2007) to define the empirical model as follows.

We first defined a system of expenditure share equations using the Almost Ideal Demand System (AIDS) proposed by Deaton and Muellbauer (1980). A system of unit value equations were then specified as proxies for prices used in the share equations and to predict the missing ones.

Following Deaton and Muellbauer, the Almost Ideal Demand System (AIDS) for the $M=12$ breakfast products can be written as

(1) $Q^{*}=A+\gamma \ln P+\theta \ln Y+\varepsilon$

where $Q^{*}$ is a vector of $M$ expenditure shares on breakfast products, $P$ is a vector of $M$ prices, and $Y=\frac{y^{*}}{P^{*}}$, the deflated total expenditures on all breakfast foods, with $y^{*}$ as total expenditures and $P^{*}$ as the translog price index. The term $\varepsilon$ is a vector of $M$ equation error terms. Household demographic variables are incorporated through transforming the intercept, $A$, in (1). That is, the intercept is defined as: $A=\alpha+\beta X$, where $X$ is a vector of $K$ demographic characteristics. Equation parameters are $\alpha(M \times 1), \beta(M \times K), \theta(M \times 1)$, and $\gamma(M \times M)$. 
Given the complexity with censoring, instead of using the non-linear AIDS specification we used the linear approximate specification (LA/AIDS), where a linear approximation to $\ln P^{*}$ is used as the expenditure deflator. Following Buse and Chan (2000), the invariant Tornqvist price index is used as a total expenditure deflator. Given the budget constraint, the expenditure shares of all 12 breakfast foods must sum to one (adding-up condition). The adding-up restriction implies that the joint density function of $\varepsilon$ is singular. Consequently, one of the $M$ share equations must be dropped during estimation. By dropping any equation from the estimation, we assume that the remaining $M-1$ share equations' error terms, $\varepsilon$ in equation (1), are distributed as a multivariate normal distribution with a joint probability density function (for more information, see Dong et al., 2007). Other theoretical conditions such as homogeneity and symmetry can also be imposed through parameter restrictions.

In (1), $\ln P$ is a vector of observed unit values as substitutes for the unobserved prices. Unit values, derived as ratios of reported expenditures to quantities, are commonly used as a proxy for prices in estimating the demands for aggregated foods (e.g., Andreya et al., 2010, and Zhen et al., 2010). For specific individual food items, unit values are their prices. However, prices for aggregated food groups are unobservable. The unit value for an aggregated food group is derived from market prices and the corresponding purchase quantities of food items within a group. Market prices vary according to quality. For example, a beef group may include less expensive cuts, such as ground beef, and more expensive steaks. Empirical studies of household food demand have shown that household characteristics affect food purchases within a food group or among groups. Therefore, unit values should be treated as endogenous and estimated jointly with the demand system. To endogenize the unit value, we define it as:

$$
\ln P=\delta Z+e
$$


where $Z$ is an $H$ column vector of geographic variables such as region and urbanicity and demographic variables that influenced the household's choice of different levels of quality in food purchases to capture price variation. $\delta$ is an $M \times H$ vector of parameters, and $e$ is an $M$ column vector of error terms.

Just like unit values, the total expenditure on breakfast foods ( $y^{*}$ in equation 1) are affected by household characteristics and were endogenized in the same manner as unit values (Dhar et al., 2003). In this study, we estimated an auxiliary regression of total expenditure on income and other household demographic variables and used the predicted total expenditure from the auxiliary regression function to replace the total expenditure, $\mathrm{y}^{*}$, used in equation (1).

The estimation of equations (1) and (2) to get the elasticities of price, total expenditure, and household demographics is fully documented in Dong et al. (2007). Conceptually, we specified the likelihood function for each household's observed purchase pattern (regime). Based on the Homescan data, each household purchase pattern fell into one of three possible regimes: (1) at least one food group was purchased, but the total number of purchased food groups was less than $M-1$, (2) $M-1$ food groups were purchased, and (3) all $M$ food groups were purchased. Depending on the household purchase pattern, a regime-specific log likelihood function is specified for the household and the sum of the log likelihood function over all households is maximized to obtain consistent and efficient parameter estimates. The zero purchase occurrences forced the likelihood function to contain high order probability integrals. In order to evaluate those integrals, a simulated probability procedure is used in the model estimation. Readers can find detailed discussion of the estimation procedure in Dong et al. (2007).

\subsection{Variables}


Table 1 reports the annual expenditure shares of the 12 food groups, $Q^{*}$ in (1), along with the portion of households who purchased the group at any point in 2006 and the unit values. In 2006, almost all households purchased bread products (99.5 percent), followed by juice (94.6 percent) and eggs (94.2 percent), and whole milk was least purchased food group with slightly more than 50 percent of all households purchased it. Breads accounted for the largest share (27.7 percent) of total expenditure on breakfast foods, followed by reduced-fat milk (12.8 percent) and juice (11.1 percent), and hot cereals had the smallest budget share at 2 percent.

[Table 1 goes here]

Homescan data indicated that consumers, on average, paid a higher price for lownutrition cereals than for high-nutrition cereals $(\$ 2.63 / \mathrm{lb}$ vs. $\$ 2.55 / \mathrm{lb})$. By applying the USDA nutrition database to the1999 Homescan data, Golub and Binkley (2005) also found that the average prices were higher for low-nutrition cereals than for high-nutrition cereals. Reduced-fat milk had a lower price than whole milk. Using the same data, Smith et al. (2009) estimated a hedonic price model for various product attributes of fluid milk (including fat content) and found significant, positive price premiums for whole milk and reduced-fat (1\% and $2 \%)$ milk $(0.153$ cent/oz and 0.065 cent/oz, respectively) above the price of skim milk.

We hypothesized that unit values, $\mathrm{P}$, and expenditure shares among the 12 food groups, Q, were influenced by an array of demographic and household grocery shopping behaviors, which are included in the $\mathrm{X}$ and $\mathrm{Z}$ vectors defined in equations (1) and (2). For example, we hypothesized that a household with a higher tendency to use coupons or buy on-sale items would pay a lower price and hence a lower unit value than is paid by other households. Similarly, the choice of store type (e.g. grocery store, super center, etc.) would affect prices because different 
store types offer different services to consumers and thus have different costs to cover through the prices they charge. The definitions and summary statistics of all influential variables are reported on table 2 .

[Table 2 goes here]

\subsection{Estimated unit values, expenditure, and censored demand}

The estimated unit values and total expenditure are shown on table 3. As expected with cross sectional data, the $\mathrm{R}^{2}$ are relatively low, ranging from 4 percent for the unit value of coffee to 19 percent for the unit value of reduced-fat milk; and 25 percent for the total expenditure.

Nevertheless many of the demographic and shopping behavior variables had a significant impact on unit values and expenditure, suggesting a reasonable goodness of fit. Judging from the $t$ statistics, household characteristics influenced the expenditure more than the unit values. The household expenditure on breakfast foods and all twelve unit values significantly (at the 1percent significance level) increased with household income. The expenditure on breakfast foods also rose with household size and number of children, but declined when the household female head (or male as the single household head) was employed. The later result may be because these families substitute eating out for grocery shopping (Hamrick and Okrent, 2014). Other factors being equal, white households spent more on breakfast foods than other households.

The shopping behaviors had a stronger influence on unit values than household characteristics. As expected, coupon use resulted in lower unit values for all 12 food groups, at the 1-percent significance level, with the largest reductions on the two RTE cereals groups. Similarly, the tendency to buy foods at discounted prices (on sale) also resulted in lower unit values at the 1-percent significance level for all foods except coffee. We grouped the food 
shopping venues into three categories—club/warehouse, convenience store, and grocery store. Grocery stores, mainly supermarkets, are the dominate venue for purchasing food (66 percent, table 2). We treated the grocery store as the base category in the unit value equation. The tendency to shop at club and warehouse stores resulted in lower unit values for all 12 food groups at the 1-percent significance level, compared to the tendency to shop at grocery stores. The tendency to shop at convenience stores lowered unit values at the 1-percent significance level for all foods except whole milk and coffee.

[Table 3 goes here]

For brevity, the parameter estimates and their significance levels for the LA/AIDS model (include the demographic variables listed in table 3 and prices listed in table 4) are reported in the appendix. Uncompensated demand own-price, cross-price, and expenditure elasticities and their associated significance levels are reported in table 4. All own-price and expenditure elasticities are significant at the 1-percent significance level and have the expected signs. Because a hypothetical price intervention on RTE cereals is the policy lever under consideration, our discussion of demand elasticities will focus on cereals own- and cross-price elasticities. Nevertheless, we note that the own-price elasticities for whole and reduced-fat milk are higher than what have been reported in the literature. As discussed below, the key demand price elasticities used to simulate dietary outcomes appeared to be reasonable.

The demand for high-nutrition cereals was more own-price elastic than low-nutrition cereals, -0.89 vs. -0.67 , implying that if the price of low- and high-nutrition cereals are both changed by the same percentage, then the high-nutrition cereals will have a larger change in quantity purchased than the low-nutrition cereals. To our knowledge, there are only a handful of studies that estimated RTE cereal demands and our elasticity estimates were comparable with 
those reported in the literature. By fitting a censored Almost Ideal Demand System to the 2006 Homescan data, Ishdorj and Jensen (2010) also found that the demand for whole-grain cereals was more own-price elastic than the demand for non-whole-grain cereals, -0.78 vs. -0.44 for uncompensated elasticities. Rahkovsky et al. (2013) estimated the demand for four nutritionsegmented RTE cereals at Hannaford Foods (a supermarket chain in the New England area of the U.S.) and Hannaford-compatible stores throughout the U.S. using store weekly sales data. They found that the demand for more nutritious RTE cereals was more own-price elastic than the demand for less nutritious RTE cereals at Hannaford-compatible stores but not at Hannaford, with uncompensated own-price elasticities ranging from -0.63 to -0.94 for Hannaford and from 1.26 to -1.84 for Hannaford-compatible stores. Chidmi and Lopez (2007) estimated the demand for 37 brands of RTE cereals in Boston and found quite elastic own-price elasticities, ranging from-2.40 to -6.49 . The high own-price elasticities for these two later studies were expected because nutrition- and brand-differentiated RTE cereals are close substitutes among themselves.

Among the 22 cross-price elasticities pertaining to RTE cereals, six of them were statistically significant at the 1-percent significance level. Cross-price elasticities suggest that complements were more common than substitutes for RTE cereals. The cross-price elasticities were small relative to the own-price elasticities. For example, the cross-price elasticities between the two types of RTE cereals were -0.01 and -0.003 , compared to the own-price elasticities of -0.67 and -0.89 for low- and high-nutrition cereals, respectively. We found an insignificant complementary relationship between high- and low-nutrition cereals, a seemingly counter-intuitive result. This result has been reported for sugar-sweetened beverage and diet drinks when the same Homescan data were analyzed (Dharmasena and Capps, 2012; Lin et al., 2011; Zhen et al., 2011). A plausible explanation is that the data were collected at the household 
level and some households may purchase both types of RTE cereals (beverages) to meet the heterogeneous demands among household members. Among the 10 non-cereals food groups, milk was a relatively strong complements of RTE cereals, but only reduced-fat milk is significant at the 1-percent significance level.

[Table 4 goes here]

\section{Simulated Dietary Outcomes of a Hypothetical Fiscal Policy}

We simulated the potential dietary outcomes of a hypothetical fiscal policy targeting RTE cereals using dietary intake data and corresponding nutrition data in NHANES. Using food descriptions we identified foods in NHANES that corresponded to the 10 non-cereals breakfast food groups, specified in the demand system. There are 209 RTE cereals in NHANES, they were classified into high- and low-nutrition cereals by applying the nutrition scoring algorithm developed for the Guiding Stars Program (Fischer et al., 2011).

We focused our outcome measures on dietary components that are relevant to RTE cereals and current priority recommendations for improvement in diet and health. The US Government's Dietary Guidelines for Americans 2010 emphasized the need to maintain energy balance for achieving a healthy weight, the low and persistent under-consumption of calcium and whole grains, and the need to moderate consumption of sodium and added sugars (USDA/USDHHS, 2010). The nutritional outcomes of interest in this study were calories, added sugars, whole grains, sodium, and calcium. While insufficient fiber intake is also a concern in American's diet, because whole grains and fiber in breakfast foods were highly correlated we included only whole grains in our simulation. 
The quantity and nutrient shares among the 12 food groups and the nutrient density (amount of the nutrient per gram or per 1000 calories) of each food group are reported in table 5. During 2005-06, RTE cereals accounted for slightly over 2 percent of the total quantity of breakfast foods by weight but had over 10 percent share of total calories and 32 percent of total added sugars, indicating that RTE cereals were relatively high in calories and especially added sugars. Breads and hot and RTE cereals were the main sources of whole grains among breakfast foods. Hot cereals had the highest whole-grain density ( 8.6 ounces per 1,000 calories), followed by high-nutrition cereals (4.3 ounces per 1,000 calories). Low-nutrition cereals (1.24 ounces per 1,000 calories) had lower whole-grain density than high-nutrition cereals, but were still high in whole-grain density relative to other breakfast foods.

[Table 5 goes here]

The NHANES data indicate that most individuals did not consume all 12 food groups on a given day, this censoring data nature represents an empirical difficulty in simulating consumption changes on an individual basis. On a given day, a person who consumed RTE cereals usually consumed either the high-nutrition or low-nutrition RTE cereals but not both. For example, 2005-06 NHANES data indicate that 36 percent of respondents consumed RTE cereals - 28 percent consumed high-nutrition cereals and 13 percent consumed low-nutrition cereals, implying that 5 percent consumed both cereals. Facing a higher price for low-nutrition cereals and a lower price for high-nutrition cereals, a consumer of low-nutrition cereals would consume less low-nutrition cereals or switch to high-nutrition cereals or other breakfast foods. The probability of switching from low-nutrition cereals to high-nutrition cereals or other breakfast foods and the corresponding consumption level needs to be estimated when we attempt 
to predict consumption changes at the individual level. Similarly, a non-consumer of RTE cereals may start consuming high-nutrition cereals when facing a lower price. The switching from zero consumption to a positive consumption, and vice versa, is also possible for the other 10 non-cereal breakfast food groups.

To circumvent the difficulty associated with censoring, we used total consumption at the population level as the base for simulation; that is, applied the estimated demand elasticities to the total U.S. consumption for the 12 food groups. We used bootstrapping to test for the statistical significance of our estimated dietary changes resulting from the hypothetical fiscal policy. We began by using unrestricted random sampling to draw 1,000 sample replicates from the NHANES data, simulated consumption changes resulting from a fiscal policy over the 1,000 samples. The final step was to estimate the means and standard deviations to represent the average and range of dietary changes.

The hypothetical fiscal policies under study included (1) a subsidy of high-nutrition cereals - 10-percent decrease in the price of high-nutrition cereals and (2) a combined subsidy of high-nutrition cereals and taxation of low-nutrition cereals - a 10-percent price increase for lownutrition cereals and a 10-percent price decrease for high-nutrition cereals. In addition, we examined the dietary consequences when the cross-price elasticities are ignored and only the own-price elasticities are included in the simulation.

Equipped with demand elasticities, we conducted a simulation of dietary outcomes resulting from the above hypothetical fiscal policies under the assumption of perfectly elastic supply of breakfast foods. This assumption implies that producers will supply the full amount demanded by consumers at the current market price and producers will not supply any if the price dips below the current market price. Therefore, consumers bear the full burden of taxation 
and reap the full benefit of subsidy - a 100-percent pass through of the fiscal policy to consumers.

We made this assumption because the supply elasticities in question are not available in the literature and because we have no data to estimate the supply of breakfast foods. In reality, supply is likely to be upward sloping and the taxation burden and subsidy benefit would be shared by producers and consumers depending on their relative price elasticities. Therefore, the assumption of perfectly price elastic supply would lead to overestimation of the changes in the prices facing consumers, consumption responses, and the subsequent changes in dietary outcomes expected from the fiscal policy.

The assumption of perfectly price elastic supply also affects the simulated cross-price effects. For example, reduced-fat milk is found to be a complement of both low- and highnutrition cereals so that the simulated reduction (increase) in reduced-fat milk consumption from taxing low-nutrition cereals (subsidizing high-nutrition cereals) is overestimated. The supply of reduced-fat milk is also likely to be imperfectly price elastic so that the price of reduced-fat milk could also be affected by the hypothetical fiscal policy and there could be a feedback effect on the price of breakfast cereals. By applying assumed supply elasticities of 1.25 to the reported demand elasticities for 10 beverage groups, Dharmasena et al. (2014) demonstrated that the assumption of perfectly price elastic supply overstates the reduction in the consumption of sugarsweetened beverages (SSB) when they are taxed. In this study, the supplies of the 12 breakfast foods are assumed to be perfectly price elastic.

The simulation results are summarized in table 6. In general, some dietary changes occurred at the 5-percent significance level, but the magnitude of changes was small. As to be expected from the estimated own-price elasticities, a subsidy of high-nutrition cereals would lead 
to increased consumption of breakfast foods, in terms of both quantity and calories. Since lownutrition cereals had higher calorie densities than high-nutrition cereals $(3.93 \mathrm{vs} .3 .63 \mathrm{kcal} / \mathrm{g}$, see table 5), we expected that a combined taxation and subsidy policy would decrease the calorie density of breakfast foods. However, we found that this policy scenario would actually increase, at the 5-percent significance level, the calorie density of breakfast foods by about 0.4 percent. When the cross-price effects were ignored in the simulation we also observed a similar increase in calorie per gram of food. This seemingly counterintuitive finding motivated us to examine the substitution among breakfast foods more closely.

[table 6 goes here]

The increase in calorie density was a result of several factors. High-nutrition cereals accounted for a larger share of breakfast quantity than low-nutrition cereals (1.5 percent vs. 0.64 percent, see table 5) and the high-nutrition cereals are more own-price elastic than low-nutrition cereals (-0.89 vs. -0.67$)$. This means that under the combined taxation and subsidy scenario, the increase in the consumption of high-nutrition cereals was more than the decrease in low-nutrition cereals. Second, among the 12 food groups RTE cereals had the highest calorie density after breakfast bars (table 5). While breakfast bars were high in calories they only accounted for a tiny share ( 0.28 percent $)$ of total grams of foods and beverages consumed at breakfast. Since beverages (milk, juice, and coffee) weigh more than food per typical serving, they had the largest shares of the total quantity consumed at breakfast and tend to be low in calorie density relative to RTE cereals. Third, the cross-price elasticities are small relative to the own-price elasticities for RTE cereals. The relatively low calorie density in breakfast foods other than RTE cereals combined with small cross-price elasticities result in a small cross-price effect on calorie density of breakfast food when RTE cereals prices are changed by fiscal policy. 
Among the four nutrients and food components we analyzed, sodium and added sugars intakes should be moderated, whereas intakes of calcium and whole grains should be encouraged (USDHHS/USDA, 2015-2020). Among the 12 breakfast foods, the meats group had the highest sodium density of 2,826 mg per 1,000 calories, followed by 1,790 mg for breads, 1,439 $\mathrm{mg}$ for low-nutrition cereals, and 1,391 mg for high-nutrition cereals. Because of the similar sodium densities of low- and high-nutrition cereals, the hypothetical fiscal policy on RTE cereals had negligible effect on sodium. RTE cereals were relatively high in added sugars and the lownutrition cereals contained more added sugars than high-nutrition cereals. Because of the relatively high added-sugar density in both types of RTE cereals, a subsidy applied to highnutrition cereals alone increased the density of added sugars in breakfast foods consumed. The combined taxation and subsidy option resulted in a small, insignificant decrease in the addedsugars density of breakfast foods from the baseline.

When the 2005 Dietary Guidelines for Americans was under deliberation, the discussion on increasing whole-grains consumption received wide-spread attention and the food industry responded by reformulating products such as RTE breakfast cereals to contain more whole grains, even before the Dietary Guidelines for Americans, 2005 was released (Mancino et al., 2008). Among the RTE cereals reported in 2005-06 NHANES, the low-nutrition cereals had a much lower whole grains content than the high-nutrition cereals- 1.24 vs. 4.31 ounces per 1,000 calories from RTE cereals. Hot cereals and breakfast bars were also rich in whole grains, 8.59 and 2.64 ounces per 1000 calories, respectively. Both the subsidy alone and combined taxation and subsidy policy scenarios resulted in a 2-percent increase, at the 5-percent significance level, in whole grains density in breakfast foods consumed. Among the 12 breakfast foods, milk, juice, and breads provided the bulk of calcium from breakfast. While RTE cereals themselves were not 
high in calcium, we hypothesized that the fiscal policy might impact calcium consumption because milk was a complement of both low- and high-nutrition cereals. However since the cross-price elasticities between the two types of milk and the two types of cereals were quite small and RTE cereals were not particularly rich in calcium, the fiscal policy simulations found no change on the calcium density from breakfast foods (table 6).

\section{Conclusions}

As policy makers and the research community evaluate policy levers to improve food choices and hence diet and health, the literature pertaining to the use of fiscal policy (subsidy and taxation) to influence food choices has grown rapidly. Contradictory results about the effectiveness of implementing fiscal policy to improve diets have been reported in the literature, suggesting that further study is still needed. In this study, we estimated a censored, price/expenditure endogenous demand system for foods commonly consumed at breakfast, including two categories of ready-to-eat breakfast cereals distinguished by their nutritional profile. The estimated demand elasticities were applied to data from a nationally representative food consumption survey to simulate the extent of dietary improvement from subsidizing highnutrition cereals and taxing low-nutrition cereals under the assumption that the supplies of all 12 breakfast foods are perfectly price elastic. We assumed perfectly price elastic supplies in this study because the literature does not have the elasticities in question and we have no data to estimate supply responses.

Ready-to-eat breakfast cereals are a popular breakfast food-38 percent of the U.S. population consumed them on a given day during 2005-06. Manipulating the relative prices of high- and low-nutrition cereals may encourage some consumers to improve the nutritional 
quality of their cereal consumption. In this study, we employed the nutrient density measurement (amount of nutrient per gram of food or per 1,000 calories) to examine the extent of dietary improvement at breakfast that might occur by subsidizing high-nutrition cereals and/or taxing low-nutrition cereals. We focused on five dietary components (food energy, added sugars, whole grains, sodium, and calcium) because of their relevance to RTE cereals and to current priority recommendations for improvement in diet and health.

Lowering the price of high-nutrition cereals by 10 percent with or without raising the price of low-nutrition cereals by 10 percent would actually increase total calories from breakfast and the amount of calories per gram of breakfast. The increase was a result of two main factors: (1) the increase in the consumption of high-nutrition cereals was greater than the decrease in the consumption of low-nutrition cereals and (2) cereals were higher in calories than the other breakfast foods chosen for this study. Even though the added-sugar density was lower for highnutrition cereals than for low-nutrition cereals, a simultaneous taxation and subsidy fiscal policy would result in a small insignificant decrease in the overall added-sugar density for breakfast foods. Moderating sodium intake is one of the priority recommendations for dietary improvement. While RTE cereals were relatively high in sodium density among the 12 breakfast foods, altering the relative prices of low- and high-nutrition cereals would not significantly change the sodium density in breakfast foods because high- and low-nutrition cereals have similar sodium densities. Since high-nutrition cereals have higher whole-grain densities than low-nutrition cereals both the subsidy alone and combined taxation and subsidy policy options would result in about a 2-percent increase in the whole-grain density of breakfast foods. 
In summary, the fiscal policy options targeting RTE breakfast cereals were found to have small effects on dietary improvements of foods consumed at breakfast under the assumption of perfectly price elastic supply. It should be pointed out that if the imperfectly price elastic supply were taken into account in this study, the simulated dietary outcomes would have been even smaller. The finding of small dietary improvement is partly because the demand for RTE breakfast cereals were own-price inelastic — a one percent change in price would result in a less than one percent change in the quantity consumed. The cross-price elasticities were found to be quite small and breakfast foods are found to be a mixture of complements and substitutes of RTE cereals so that the net cross-price effect between RTE cereals and other foods was found to be small. Thus the fiscal policy options considered here would have limited impact on the overall healthfulness of the breakfast choices of Americans.

In this study we used 2006 household purchase data to estimate the demand for breakfast foods, and the dietary intake and nutrition data from the 2005-6 National Health and Examination Survey (NHANES) to run our simulations. More recent household purchase and dietary intake data were available when we began our study, but these were the latest data available that are not affected by the recession of 2007-09. A limitation in using 2006 purchase data is that the data do not capture new or reformulated food products introduced by the food industry in response to recent Federal dietary recommendations, such as encourage consumption of whole grains and moderate sodium intake. In addition to the need to evaluate potential dietary outcomes using more recent purchase and consumption data, future research is also needed to evaluate implementing a broad-based fiscal policy to a wide range of nutrition-varying food items, such as snacks, breads and sweet goods, and highly processed foods which are ready to serve with little or no preparation. 


\section{References}

Andreyeva T, MW Long, and KD Brownell. "The Impact of Food Prices on Consumption: A Systematic Review of Research on the Price Elasticity of Demand for Food." American. J Public Health 2010 (100), 216-222.

Agricultural Research Service, U.S. Department of Agriculture. Food and Nutrient Database for Dietary Studies. 2015. http://www.ars.usda.gov/News/docs.htm?docid=12089 (accessed February 23, 2015)

Bartlett S, J Klerman, L Olsho, et al. Evaluation of the Healthy Incentives Pilot (HIP): Final Report. Prepared by Abt Associates for the U.S. Department of Agriculture, Food and Nutrition Service. September, 2014. http://www.fns.usda.gov/healthy-incentives-pilotfinal-evaluation-report.

Buse A and WH Chan. "Invariance, Price Indices and Estimation in Almost Ideal Demand Systems." Empirical Economics 2000 (25), 519-39.

Capacci S, M Mazzocchi, B Shankar, et al., "Policies to Promote Healthy Eating in Europe: A Structured Review of Policies and Their Effectiveness." Nutrition Reviews 2012(70), 188-200.

Cawley J and C Meyerhoefer. "The Medical Care Costs of Obesity: An Instrumental Variables Approach." J Health Economics 2012(31), 219-230.

Centers for Disease Control and Prevention, U.S. Department of Health and Human Services. Chronic Diseases and Health Promotion. http://www.cdc.gov/chronicdisease/overview/ (Accessed February 23, 2015)

Centers for Disease Control and Prevention, National Center for Health Statistics (CDC/NCHS) US Department of Health and Human Services. National Health and Nutrition Examination Survey, 2005-2006, http://www.cdc.gov/nchs/nhanes/wweia.htm (downloaded 2009)

Chidmi B and R Lopez. "Brand-Supermarket Demand for Breakfast Cereals and Retail Competition.” American J Agricultural Economics 2007 (89), 324-337

Cornelsen L, R Green, R Tucker, et al. "What Happens to Patterns of Food Consumption When Food Prices Change? Evidence from a Systematic Review and Meta-Analysis of Food Price Elasticities Globally." Health Economics. 2014 Wiley Online Library DOI: 10.1002/hec.3107.

Deaton A and J Muellbauer. "An Almost Ideal Demand System.” American Economic Review 1980 (70), 312-336.

Dhar T, JP Chavas, and BW Gould. "An Empirical Assessment of Endogeneity Issues in Demand Analysis for Differentiated Products." American J Agricultural Economics 2003 (85), 605-617.

Dharmasena S, GC Davis and O Capps, Jr. "Partial versus General Equilibrium Calorie and Revenue Effects Associated with a Sugar-Sweetened Beverage Tax." J Agricultural and Resource Economics 2014(39),157-174

Dharmasena S, and O Capps, Jr. "Intended and Unintended Consequences of a Proposed National Tax on Sugar-Sweetened Beverages to Combat the U.S. Obesity Problem." Health Economics 2012(21),669-694 
Dietary Guidelines Advisory Committee. 2015. Scientific Report of the 2015 Dietary Guidelines Advisory Committee to the Secretary of Health and Human Services and the Secretary of Agriculture. http://www.health.gov/dietaryguidelines/2015-scientific-report/. (Accessed July 20, 2015)

Dong D, H Kaiser, and O Myrland. "Quantity and Quality Effects of Advertising: A Demand System Approach.” Agricultural Economics 2007 (36), 313-324.

Duffey KJ, P Gordon-Larsen, JM Shikany, et al. "Food Prices and Diet and Health Outcomes: 20 Years of the CARDIA Study." Archives Internal Medicine 2010(170), 420-426.

Einav L, E Leibtag, and A Nevo. On the Accuracy of Nielsen Homescan Data. Economic Research Report \#69. Economic Research Service, U.S. Department of Agriculture. December 2008.

Finkelstein E, C Zhen, J Nonnemaker, and JE Todd. "Impact of Targeted Beverage Taxes on High- and Low-Income Households." Archives Internal Medicine 2010(170), 20283032.

Finkelstein E, J Trogdon, J Cohen, and W Dietz. "Annual Medical Spending Attributable To Obesity: Payer-And Service-Specific Estimates." Health Affairs 2009(28), 822-831.

Fischer L, L Sutherland, L Kaley, et al. "Development and Implementation of the Guiding Stars Nutrition Guidance Program." American J Health Promotion 2011(26), 55-63.

Fletcher JM, D Frisvold, and N Tefft. "Can Soft Drink Taxes Reduce Population Weight?” Contemporary Economic Policy 2010(28), 23-35.

Food and Drug Administration, U.S. Department of Health and Human Services. Labeling \& Nutrition. http://www.fda.gov/Food/IngredientsPackagingLabeling/LabelingNutrition/default.htm. (accessed February 23, 2015)

Food and Nutrition Service, U.S. Department of Agriculture. Healthy Incentives Pilot. http://www.fns.usda.gov/hip/healthy-incentives-pilot. (accessed February 23, 2015).

French SA, RW Jeffery, M Story, et al. "Pricing and Promotion Effects on Reduced-fat Vending Snack Purchases: the Chips Study." American J Public Health 2001(91), 112-117.

French SA, M Story, J Fulkerson, and A Gerlach. "Food Environment in Secondary Schools: À La Carte, Vending Machines, and Food Policies and Practices." American J Public Health 2003(93), 1161-1168.

Gladson. Gladson Nutrition Database. http://www.gladson.com/Our-Services/NutritionDatabase (accessed February 27, 2015).

Golub A and JJ Binkley. Consumer Choice of Breakfast Cereals. Selected paper presented at the 2005 AAEA meetings, July 24-27, 2005. Providence, RI.

Guthrie J, T Smith, and BH Lin. Linking Federal Food Intake Surveys Provides a More Accurate Look at Eating Out Trends. Amber Waves, Economic Research Service, U.S. Department of Agriculture. 2016. http://ers.usda.gov/amber-waves/2016-june/linkingfederal-food-intake-surveys-provides-a-more-accurate-look-at-eating-outtrends.aspx\#.V2GundkrI1I

Hamrick K and A Okrent. The Role of Time in Fast-Food Purchasing Behavior in the United States. ERR 178. Economic Research Service, U.S. Department of Agriculture. November 2014.

Ishdorj A and HH Jensen. Demand for Breakfast Cereals: Whole Grains Guidance and Food Choice. Selected paper presented at the first joint EAAE/AAEA seminar, September 1517, 2010. Freising, Germany. 
Kuchler F, A Tegene A, and JM Harris. "Taxing Snack Foods: Manipulating Diet Quality or Financing Information Program? "Review of Agricultural Economics 2005(27), 4-20.

Lin BH, ST Yen, D Dong, and DS Smallwood. "Economic Incentives for Dietary Improvement among Food Stamp Recipients.” Contemporary Economic Policy 2010(28), 524-536.

Lin BH, T Smith, JY Lee, and KD Hall. "Measuring Weight Outcomes for Obesity Intervention Strategies: The Case of a Sugar-Sweetened Beverage Tax." Economics and Human Biology 2011(9), 329-341.

Lin BH, J Guthrie, I Rahkovsky, et al. "Simulating the Potential Effects of a Shelf-Tag Nutrition Information Program and Pricing on Diet Quality Associated with Ready-to-Eat Cereals." International Food and Agribusiness Management Review 2014(17), 7-24

Mancino L, F Kuchler, and E Leibtag. "Getting Consumers to Eat More Whole-grains: the Role of Policy, Information, and Food Manufacturers.” Food Policy 2008(33), 489-496.

McCloskey DN. The Applied Theory of Price. 2nd edition. London: Collier Macmillan Publishers, 1982.

Meyerhoefer C and E Leibtag. "A Spoonful of Sugar Helps the Medicine Go Down: the Relationship Between Food Prices and Medical Expenditures on Diabetes." American J Agricultural Economics 2010 (92), 1271-1282.

Mytton O, D Clarke, and M Rayner. "Taxing Unhealthy Food and Drinks to Improve Health." BMJ, 2012(344), 29-31.

Ogden CL, MD Carroll, BK Kit, and KM Flegal. "Prevalence of Childhood and Adult Obesity in the United States, 2011-2012." J American Medical Association 2014(311), 806-814.

Oliveira V. The Food Assistance Landscape: FY 2013 Annual Report. Economic Information Bulletin \#120. Economic Research Service, U.S. Department of Agriculture. 2014.

Powell LM, JF Chriqui, T Khan, et al. "Assessing the Potential Effectiveness of Food and Beverage Taxes and Subsidies for Improving Public Health: a Systematic Review of Prices, Demand and Body Weight Outcomes." Obesity Review 2013(14), 110-128.

Rahkovsky I and CA Gregory. "Food Prices and Blood Cholesterol." Economics and Human Biology 2013(11), 95-107.

Rahkovsky I, BH Lin, C Lin, and JY Lee. "Effects of the Guiding Stars Program on Purchases of Ready-to-Eat Cereals with Different Nutritional Attributes." Food Policy 2013(43), 100107.

Sharma A, K Hauck, B Hollingsworth and L Sicilani. "The Effects of Taxing Sugar-Sweetened Beverages across Different Income Groups." Health Economics 2014(23), 1159-1184.

Smith T, CL Huang, and BH Lin. "Estimating Organic Premiums in the US Fluid Milk Market." Renewable Agriculture and Food Systems 2009(24), 197-204.

Thow AM, S Jan, S Leeder, and B Swinburn. "The Effect of Fiscal Policy on Diet, Obesity and Chronic Disease: a Systematic Review." Bulletin of the World Health Organization 2010(88), 1-6.

Thow AM, S Downs, and S Jan. "A Systematic Review of the Effectiveness of Food Taxes and Subsidies to Improve Diets: Understanding the Recent Evidence." Nutrition Reviews Online 2014: doi:10.1111/nure.12123.

Tiffin R, A Kehlbacher, and M Salois. "The Effects of a Soft Drink Tax in the UK." Health Economics 2014 Wiley Online Library DOI: 10.1002/hec.3046.

Todd JE. Changes in Eating Patterns and Diet Quality among Working-Age Adults, 2005-2010. Economic Research Report No. 161. Economic Research Service, U.S. Department of Agriculture. January 2014 
U.S. Department of Agriculture and U.S. Department of Health and Human Services (USDA and USDHHS), Dietary Guidelines for Americans, 2010. $7^{\text {th }}$ Edition, Washington, D.C.: U.S. Government Printing Office, December. 2010.

U.S. Department of Health and Human Services and U.S. Department of Agriculture. 2015 2020 Dietary Guidelines for Americans. $8^{\text {th }}$ Edition. December 2015. Available at http://health.gov/dietaryguidelines/2015/guidelines/

Zhen C, EA Finkelstein, JM Nonemaker, SA Karns, and JE Todd. "Predicting the Effects of Sugar-Sweetened Beverage Taxes on Food and Beverage Demand in a Large Demand System". American J Agricultural Economics 2013(96), 1-25.

Zhen C, MK Wohlgenant, S Karns, and P Kaufman. 2010. "Habit Formation and Demand for Sugar-Sweetened Beverages." American J Agricultural Economics 2010(93), 175-193 
Table 1. Purchasing proportions, budget shares, and unit values of the 12 breakfast food groups

\begin{tabular}{lrrl}
\hline & $\begin{array}{c}\text { Purchasing } \\
\text { proportions }(\%)^{1}\end{array}$ & $\begin{array}{c}\text { Budget } \\
\text { shares }(\%)\end{array}$ & \multicolumn{1}{l}{ Unit } \\
& 85.90 & 12.83 & $3.45 \$ /$ gal \\
\hline Reduced fat milk & 52.26 & 4.05 & $4.12 \$ /$ gal \\
Whole milk & 77.29 & 5.66 & $1.41 \$ / \mathrm{lb}$ \\
Yogurt & 94.18 & 4.01 & $0.85 \$ / \mathrm{lb}$ \\
Eggs & 68.69 & 2.03 & $2.02 \$ / \mathrm{lb}$ \\
Hot cereals & 63.69 & 3.00 & $4.45 \$ / \mathrm{lb}$ \\
Breakfast bar & 94.63 & 11.05 & $5.05 \$ / \mathrm{gal}$ \\
Juice & 73.19 & 6.48 & $2.38 \$ /$ gal \\
Coffee & 93.32 & 10.89 & $2.39 \$ / \mathrm{lb}$ \\
Meats & 99.46 & 27.71 & $1.35 \$ / \mathrm{lb}$ \\
Breads & 74.76 & 4.45 & $2.63 \$ / \mathrm{lb}$ \\
Low-nutrition cereals & 89.44 & 7.82 & $2.55 \$ / \mathrm{lb}$ \\
\hline High-nutrition cereals &
\end{tabular}

1. The percent of households that purchased the food group in 2006.

Source: Authors' calculation based on the 2006 Homescan Fresh Food Panel $(n=7,528)$ 
Table 2. Definitions of expanatory variables in the demand system: 2006 Homescan household data

\begin{tabular}{|c|c|c|c|}
\hline \multirow[b]{2}{*}{ Variable } & \multirow[b]{2}{*}{ Definition } & \multicolumn{2}{|c|}{ Sampe $(\mathrm{n}=7,528)$} \\
\hline & & Mean & Std Dev \\
\hline \multicolumn{4}{|c|}{ Shopping behavior } \\
\hline Coupon & Share of breakfast food expenditure paid with coupon use (\%) & 4.51 & 7.67 \\
\hline Discount & Share of breakfast food expenditure paid with discounted price (\%) & 24.60 & 22.21 \\
\hline Convenient & Share of breakfast food expenditure - convenience and drug store $(\%)$ & 13.56 & 19.62 \\
\hline Club & Share of breakfast food expenditure - club, super center, and mass merchandizer (\%) & 20.79 & 24.62 \\
\hline Grocery & Share of breakfast food expenditure - grocery store $(\%)$ & 65.64 & 28.30 \\
\hline \multicolumn{4}{|c|}{ Househoold characteristics } \\
\hline HHSIZE & Household size & 2.31 & 1.29 \\
\hline PIR & Poverty income ratio (\%), income as $\%$ of the poverty line & 426.03 & 279.90 \\
\hline H_age & Age of the female head or male head if no female & 52.93 & 10.64 \\
\hline H_work & Work status of female head or male head if no female $(0,1)$ & 0.73 & 0.45 \\
\hline Married & Martial status $(0,1)$ & 0.57 & 0.49 \\
\hline College & Household head attended college & 0.73 & 0.44 \\
\hline Boy_6 & Number of boys $<7$ in age & 0.03 & 0.19 \\
\hline Girl_6 & Number of girls $<7$ in age & 0.04 & 0.20 \\
\hline Boy_12 & Number of boys $7-12$ & 0.07 & 0.31 \\
\hline Girl_12 & Number of girls $7-12$ & 0.07 & 0.29 \\
\hline Boy_17 & Number of boys $13-17$ & 0.07 & 0.29 \\
\hline Girl_17 & Number of girls 13 - 17 & 0.07 & 0.28 \\
\hline White & Race - White & 0.74 & 0.44 \\
\hline Black & Race - Black & 0.13 & 0.34 \\
\hline Hispanic & Race - Hispanic & 0.03 & 0.17 \\
\hline Othrace & Race - others & 0.10 & 0.30 \\
\hline Rural & Rural area & 0.06 & 0.24 \\
\hline East & Region - East & 0.22 & 0.42 \\
\hline West & Region - West & 0.38 & 0.49 \\
\hline Central & Region - Central & 0.17 & 0.37 \\
\hline South & Region - South & 0.23 & 0.42 \\
\hline
\end{tabular}

Source: Authors' calculation based on the 2006 Homescan Fresh Food Panel 


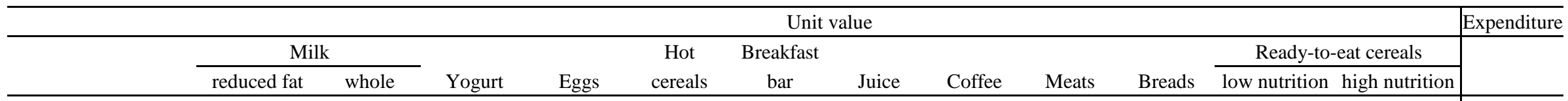

Shopping behavior

Coupon

Discount

Convenient

Club

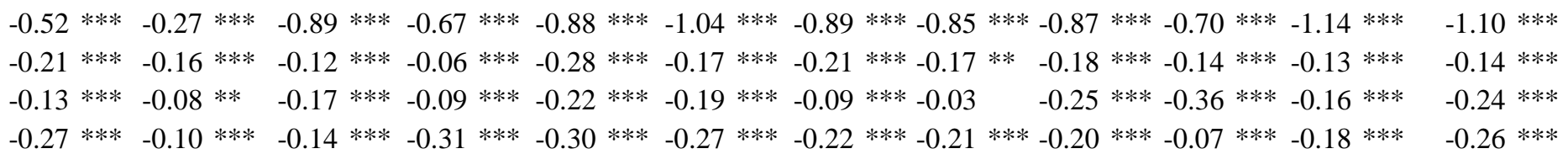

\begin{tabular}{|c|c|c|c|c|c|c|c|c|c|c|c|c|c|c|c|}
\hline \multicolumn{16}{|c|}{ Household Characteristics } \\
\hline Constant & $0.98 * * *$ & $0.99 * * *$ & $0.24 * *$ & $-0.23 *$ & $1.16 * * *$ & $0.89 * * *$ & $1.13 * * *$ & -2.41 & $* * *$ & -0.47 & $* * *$ & $0.37 * *$ & $0.45 * * *$ & $0.47 * * *$ & $4.66 * * *$ \\
\hline 1/HHSIZE & $0.21 * * *$ & $0.25 * * *$ & 0.04 & 0.02 & 0.03 & $0.10 * * *$ & $0.14 * * *$ & 0.46 & $* * *$ & 0.16 & $* * *$ & $0.05 *$ & $0.06 * *$ & $0.05 * *$ & $-0.79 * * *$ \\
\hline $\ln ($ Income $)$ & $0.02 * * *$ & $0.04 * * *$ & $0.05 * * *$ & $0.05 * * *$ & $0.08 * * *$ & $0.07 * * *$ & $0.07 * * *$ & 0.20 & $* * *$ & 0.09 & $* * *$ & $0.08 * * *$ & $0.06 * * *$ & $0.05 * * *$ & $0.06 * * *$ \\
\hline $\ln \left(\mathrm{H} \_\right.$age $)$ & 0.00 & -0.03 & $-0.10 * * *$ & $-0.07 * * *$ & $-0.30 * * *$ & -0.01 & -0.03 & -0.07 & & 0.12 & $* * *$ & $-0.21 * * *$ & -0.02 & 0.01 & $0.26 * * *$ \\
\hline Boy_6 & 0.01 & $-0.07 * *$ & 0.03 & -0.02 & -0.04 & $-0.05 *$ & -0.02 & 0.10 & & 0.00 & & 0.00 & 0.02 & 0.02 & $0.13 * * *$ \\
\hline Girl_6 & 0.00 & -0.04 & 0.02 & 0.00 & -0.03 & $-0.05 *$ & -0.02 & 0.03 & & -0.01 & & $-0.05 *$ & -0.02 & 0.00 & $0.13 * * *$ \\
\hline Boy_12 & -0.02 & -0.01 & 0.01 & -0.01 & -0.02 & $-0.05 * * *$ & $-0.03 * *$ & 0.03 & & -0.04 & $* *$ & -0.01 & -0.01 & -0.01 & $0.08 * * *$ \\
\hline Girl_12 & 0.00 & 0.02 & $0.04 * * *$ & -0.02 & 0.01 & $-0.03 *$ & -0.02 & 0.00 & & 0.02 & & $-0.04 *$ & -0.02 & -0.01 & $0.09 * * *$ \\
\hline Boy_17 & $-0.05 * * *$ & -0.03 & -0.01 & 0.00 & -0.03 & $-0.07 * * *$ & $-0.04 * * *$ & -0.11 & $*$ & -0.07 & $* * *$ & $-0.08 * * *$ & $-0.03 * *$ & $-0.03 *$ & $0.16 * * *$ \\
\hline Girl_17 & $-0.03 *$ & 0.00 & -0.02 & 0.00 & -0.02 & $-0.04 * *$ & $-0.05 * * *$ & -0.06 & & -0.06 & $* * *$ & -0.01 & 0.00 & 0.01 & $0.08 * * *$ \\
\hline College & 0.00 & $0.03 * *$ & 0.00 & 0.01 & 0.02 & $0.02 *$ & 0.01 & 0.05 & & 0.04 & $* * *$ & $0.03 * *$ & 0.01 & 0.00 & 0.01 \\
\hline H_work & $0.04 * * *$ & $0.04 * *$ & 0.01 & -0.01 & 0.02 & 0.01 & 0.01 & -0.01 & & -0.01 & & 0.01 & 0.00 & 0.01 & $-0.07 * * *$ \\
\hline Black & $0.14 * * *$ & 0.02 & $0.02 *$ & $0.06 * * *$ & $-0.19 * * *$ & -0.02 & $-0.03 * *$ & -0.23 & $* * *$ & -0.04 & $* *$ & -0.01 & $-0.03 * *$ & $0.03 * *$ & $-0.21 * * *$ \\
\hline Hispanic & $0.06 * * *$ & -0.03 & -0.03 & 0.03 & 0.04 & 0.00 & $-0.05 * *$ & 0.10 & & 0.03 & & $-0.08 * *$ & 0.00 & 0.00 & $-0.08 * *$ \\
\hline Othrace & $0.07 * * *$ & -0.01 & 0.00 & $0.05 * * *$ & -0.02 & 0.02 & -0.02 & 0.08 & & 0.01 & & $-0.07 * * *$ & 0.01 & 0.01 & $-0.18 * * *$ \\
\hline Rural & 0.01 & -0.05 & -0.03 & $-0.07 * * *$ & $-0.07 *$ & -0.04 & $-0.08 * * *$ & 0.00 & & -0.11 & $* * *$ & $-0.04 *$ & $-0.07 * * *$ & $-0.04 * *$ & $-0.06 *$ \\
\hline Married & $-0.03 * *$ & -0.01 & $-0.02 * *$ & $-0.02 *$ & $-0.10 * * *$ & $-0.04 * *$ & $-0.04 * * *$ & 0.00 & & -0.03 & $* *$ & $-0.04 * * *$ & $-0.04 * * *$ & $-0.04 * * *$ & $0.18 * * *$ \\
\hline East & $0.03 * *$ & $-0.08 * * *$ & $-0.02 *$ & $-0.13 * * *$ & $-0.12 * * *$ & -0.03 & $-0.06 * * *$ & -0.39 & $* * *$ & -0.04 & $* *$ & $-0.13 * * *$ & 0.00 & 0.01 & $0.07 * * *$ \\
\hline Central & $-0.20 * * *$ & $-0.11 * * *$ & $-0.04 * * *$ & $-0.31 * * *$ & $-0.16 * * *$ & -0.03 & $-0.11 * * *$ & -0.07 & & -0.03 & & $-0.06 * * *$ & $-0.04 *$ & -0.02 & 0.04 \\
\hline West & $0.07 * * *$ & -0.01 & $-0.08 * * *$ & $-0.27 * * *$ & $-0.20 * * *$ & -0.02 & $-0.08 * * *$ & -0.18 & $* * *$ & -0.04 & $* * *$ & $-0.08 * * *$ & $-0.07 * * *$ & $-0.02 * *$ & 0.01 \\
\hline R-squared & 0.19 & 0.07 & 0.11 & 0.17 & 0.09 & 0.10 & 0.11 & 0.04 & & 0.09 & & 0.08 & 0.09 & 0.14 & 0.25 \\
\hline
\end{tabular}

Sample size $=7,528 . * * *, * *$, and $*$ denote the 1,5 , and $10 \%$ significance level, respectively. 
Table 4. Uncompensated demand elasticities

\begin{tabular}{|c|c|c|c|c|c|c|c|c|c|c|c|c|c|}
\hline & \multicolumn{12}{|c|}{ Uncompensated Price elasticities } & \multirow{3}{*}{$\begin{array}{c}\text { Expenditure } \\
\text { elasticities } \\
\end{array}$} \\
\hline & \multicolumn{2}{|c|}{ Milk } & \multirow[b]{2}{*}{ Yogurt } & \multirow[b]{2}{*}{ Eggs } & \multirow{2}{*}{$\begin{array}{c}\text { Hot } \\
\text { cereals }\end{array}$} & \multicolumn{2}{|l|}{ Breakfast } & \multirow[b]{2}{*}{ Coffee } & \multirow[b]{2}{*}{ Meats } & \multirow[b]{2}{*}{ Breads } & \multicolumn{2}{|c|}{ Ready-to-eat cereals } & \\
\hline & reduced fat & whole & & & & bar & Juice & & & & low nutrition & igh nutrition & \\
\hline Milk - reduced fat & $-1.371 * * *$ & $0.288 * * *$ & $-0.052 * * *$ & $-0.028 * * *$ & -0.002 & $-0.040 * * *$ & $-0.040 * *$ & $-0.015 *$ & -0.007 & -0.010 & $-0.051 * * *$ & $-0.145 * * *$ & $1.475^{* * *}$ \\
\hline Milk - whole & $0.673 * * *$ & $-1.721 * * *$ & 0.000 & -0.013 & -0.023 & -0.013 & $-0.087 * *$ & -0.011 & -0.017 & -0.015 & -0.047 & -0.016 & $1.289 * * *$ \\
\hline Yogurt & 0.017 & -0.004 & $-0.671 * * *$ & -0.022 & -0.023 & 0.025 & $0.116 * * *$ & $-0.025 * *$ & -0.008 & $0.071 * * *$ & 0.021 & -0.042 & $0.544^{* * *}$ \\
\hline Eggs & -0.016 & -0.012 & $-0.072 * * *$ & $-0.402 * * *$ & $-0.070 * * *$ & -0.016 & -0.031 & $-0.028 * * *$ & $-0.065 * * *$ & $-0.154 * * *$ & $-0.067 * * *$ & $-0.075 * * *$ & $1.007 * * *$ \\
\hline Hot cereals & 0.037 & -0.049 & $-0.067 * *$ & $-0.088 * * *$ & $-0.740 * * *$ & $0.059 * *$ & 0.003 & $-0.048 * * *$ & -0.013 & 0.005 & 0.025 & -0.012 & $0.888 * * *$ \\
\hline Breakfast bar & -0.026 & -0.026 & 0.050 & 0.004 & $0.045 * *$ & $-0.732 * * *$ & 0.025 & -0.007 & 0.038 & $0.098 * * *$ & -0.002 & 0.033 & $0.502 * * *$ \\
\hline Juice & 0.024 & $-0.040 * *$ & $0.033 * *$ & -0.011 & -0.003 & -0.012 & $-0.956 * * *$ & $-0.017 * *$ & -0.024 & $-0.049 * * *$ & -0.009 & $0.038 * *$ & $1.024 * * *$ \\
\hline Coffee & $0.077 * * *$ & -0.007 & $-0.031 * * *$ & 0.000 & $-0.015 * * *$ & $-0.014 *$ & $0.024 *$ & $-0.741 * * *$ & 0.006 & $0.037 * *$ & -0.007 & $0.028 * * *$ & $0.643 * * *$ \\
\hline Meats & $0.086 * * *$ & -0.005 & -0.033 & $-0.022 * * *$ & -0.004 & -0.001 & -0.004 & $-0.016 *$ & $-0.780 * * *$ & $-0.055 * * *$ & $-0.018 * * *$ & 0.013 & $0.840^{* * *}$ \\
\hline Breads & $0.095 * * *$ & 0.004 & -0.016 & $-0.029 * * *$ & -0.002 & $-0.006 * * *$ & $-0.019 *$ & $-0.023 * * *$ & $-0.044 * * *$ & $-0.955 * * *$ & 0.010 & 0.012 & $0.973 * * *$ \\
\hline Nutrition low cereals & $-0.150 * * *$ & -0.076 & 0.008 & $-0.084 * * *$ & 0.016 & -0.022 & -0.049 & $-0.053 * * *$ & $-0.083 * * *$ & -0.007 & $-0.673 * * *$ & -0.010 & $1.183 * * *$ \\
\hline Nutrition high cereals & $-0.083 * * *$ & -0.014 & $-0.032 * * *$ & $-0.022 * * *$ & -0.004 & 0.000 & 0.016 & -0.005 & -0.009 & -0.012 & -0.003 & $-0.893 * * *$ & $1.062 * * *$ \\
\hline
\end{tabular}

Notes: $* * *, * *$, and $*$ denote the 1,5 , and 10 -percent significance level, respectively 
Table 5. Nutrient share and density of breakfast foods: U.S. population

\begin{tabular}{|c|c|c|c|c|c|c|c|c|c|c|c|c|}
\hline & \multicolumn{2}{|c|}{ Milk } & \multirow[b]{2}{*}{ Yogurt } & \multirow[b]{2}{*}{ Eggs } & \multirow{2}{*}{$\begin{array}{c}\text { Hot } \\
\text { cereals }\end{array}$} & \multirow{2}{*}{$\begin{array}{c}\text { Breakfast } \\
\text { bar }\end{array}$} & \multirow[b]{2}{*}{ Juice } & \multirow[b]{2}{*}{ Coffee } & \multirow[b]{2}{*}{ Meats } & \multirow[b]{2}{*}{ Breads } & \multicolumn{2}{|c|}{ Ready-to-eat cereals } \\
\hline & reduced fat & whole & & & & & & & & & low nutrition & high nutrition \\
\hline \multicolumn{13}{|l|}{ US population } \\
\hline \multicolumn{13}{|l|}{ Shares $(\%)$ of all breakfast foods } \\
\hline Quantity & 14.80 & 11.07 & 1.80 & 0.88 & 2.79 & 0.28 & 12.68 & 37.26 & 6.72 & 9.58 & 0.64 & 1.50 \\
\hline Calories & 9.49 & 7.25 & 2.11 & 2.04 & 3.02 & 1.57 & 7.73 & 1.47 & 18.17 & 36.83 & 3.28 & 7.04 \\
\hline Added sugars & 3.21 & 2.08 & 8.92 & 0.00 & 3.15 & 4.80 & 1.74 & 3.52 & 0.13 & 40.92 & 16.10 & 15.44 \\
\hline Whole grains & 0.00 & 0.00 & 0.00 & 0.00 & 25.01 & 3.99 & 0.00 & 0.00 & 0.00 & 37.83 & 3.92 & 29.25 \\
\hline Sodium & 5.45 & 3.87 & 0.88 & 2.23 & 2.46 & 0.56 & 0.62 & 1.10 & 32.26 & 41.44 & 2.97 & 6.15 \\
\hline Calcium & 30.02 & 22.17 & 4.73 & 0.83 & 2.65 & 0.67 & 10.16 & 2.92 & 2.16 & 17.67 & 1.47 & 4.55 \\
\hline \multicolumn{13}{|l|}{ Nutrient density } \\
\hline Calories (kcal/g) & 0.49 & 0.51 & 0.91 & 1.80 & 0.83 & 4.25 & 0.47 & 0.03 & 2.08 & 2.96 & 3.93 & 3.63 \\
\hline Added sugars (tsp/1000 kcal) & 1.69 & 1.43 & 21.03 & 0.00 & 5.19 & 15.26 & 1.12 & 11.96 & 0.03 & 5.54 & 24.44 & 10.93 \\
\hline Whole grains (oz/1000 kcal) & 0.00 & 0.00 & 0.00 & 0.00 & 8.59 & 2.64 & 0.00 & 0.00 & 0.00 & 1.07 & 1.24 & 4.31 \\
\hline Sodium (mg/1000 kcal) & 914.03 & 849.62 & 661.47 & 1736.72 & 1296.78 & 571.67 & 127.07 & 1194.69 & 2826.28 & 1790.47 & 1439.23 & 1390.76 \\
\hline Calcium (mg/1000 kcal) & 2404.54 & 2323.04 & 1700.60 & 310.12 & 667.19 & 326.28 & 999.33 & 1514.52 & 90.38 & 364.62 & 339.07 & 490.82 \\
\hline
\end{tabular}

Source: NHANES 2005-06 
Table 6. Simulated dietary improvement from fiscal policy

\begin{tabular}{|c|c|c|c|c|c|c|c|}
\hline & \multirow[t]{2}{*}{ Baseline } & \multicolumn{2}{|c|}{ Taxation and subsidy } & \multirow{2}{*}{$\begin{array}{l}\text { Only } \\
\text { subsidy }\end{array}$} & \multicolumn{2}{|c|}{ Taxation and subsidy } & \multirow{2}{*}{$\begin{array}{c}\text { Only } \\
\text { subisdy }\end{array}$} \\
\hline & & $\begin{array}{l}\text { with } \\
\text { cross-price }\end{array}$ & $\begin{array}{l}\text { without } \\
\text { e effects }\end{array}$ & & $\begin{array}{l}\text { with } \\
\text { cross-pric }\end{array}$ & $\begin{array}{l}\text { without } \\
\text { e effects }\end{array}$ & \\
\hline & [1] & [2] & [3] & [4] & {$[2] /[1] * 100$} & {$[3] /[1] * 100$} & {$[4] /[1] * 100$} \\
\hline Total calories [calories in million] & 31344 & 31466 & 31471 & 31563 & 1.0039 & 1.0041 & 1.0070 \\
\hline Total quantity [grams in million] & 40649 & 40651 & 40686 & 40735 & 1.0000 & 1.0009 & 1.0021 \\
\hline Calories per gram & 0.7711 & 0.7741 & 0.7736 & 0.7749 & 1.0039 & 1.0032 & 1.0049 \\
\hline $95 \%$ confidence limits & {$[0.7707,0.7715]$} & {$[0.7737,0.7745]$} & {$[0.7732,0.7740]$} & {$[0.7745,0.7753]$} & & & \\
\hline Added sugar density [tsp/1000 kcal] & 4.9872 & 4.9852 & 4.9815 & 5.0213 & 0.9996 & 0.9989 & 1.0068 \\
\hline $95 \%$ confidence limits & {$[4.9843,4.9900]$} & {$[4.9823,4.9880]$} & {$[4.9786,4.9843]$} & {$[5.0185,5.0241]$} & & & \\
\hline Whole grain density ]g/1000 kcal] & 1.0371 & 1.0580 & 1.0571 & 1.0565 & 1.0202 & 1.0193 & 1.0187 \\
\hline $95 \%$ confidence limits & {$[1.0361,1.0381]$} & {$[1.0570,1.0590]$} & {$[1.0561,1.0581]$} & {$[1.0555,1.0575]$} & & & \\
\hline Sodium density [mg/1000 kcal] & 1591 & 1589 & 1590 & 1589 & 0.9987 & 0.9994 & 0.9987 \\
\hline $95 \%$ confidence limits & {$[1591,1592]$} & {$[1589,1590]$} & {$[1590,1591]$} & {$[1588,1589]$} & & & \\
\hline Calcium density $[\mathrm{mg} / 1000 \mathrm{kcal}]$ & 760 & 761 & 759 & 761 & 1.0013 & 1.0013 & 1.0013 \\
\hline $95 \%$ confidence limits & {$[759,760]$} & {$[760,761]$} & {$[759,759]$} & {$[760,761]$} & & & \\
\hline
\end{tabular}

Numbers with gray-colored background are significantly different from the baseline figures at the 5-percent significance level. 
Appendix table. Paramter estimates of the Almost Ideal Demand system

\begin{tabular}{|c|c|c|c|c|c|c|c|c|c|c|c|c|}
\hline & \multicolumn{2}{|c|}{ Milk } & \multirow[b]{2}{*}{ Yogurt } & \multirow[b]{2}{*}{ Eggs } & \multirow[b]{2}{*}{ Hot cereals } & \multirow[b]{2}{*}{ Breakfast bar } & \multirow[b]{2}{*}{ Juice } & \multirow[b]{2}{*}{ Coffee } & \multirow[b]{2}{*}{ Meats } & \multirow[b]{2}{*}{ Breads } & \multicolumn{2}{|c|}{ Nutrition } \\
\hline & reduced fat & whole & & & & & & & & & low cereals & high cereals ${ }^{1}$ \\
\hline \multicolumn{13}{|l|}{ Shopping behavior } \\
\hline Coupon & $-0.001 * * *$ & $-0.001 * * *$ & $0.001 * * *$ & $0.000 * * *$ & 0.000 & $0.001 * * *$ & 0.000 & $0.001 * * *$ & $-0.001 * * *$ & $-0.001 * * *$ & 0.000 & 0.001 \\
\hline Discount & 0.000 & $0.000 * * *$ & $0.000 * * *$ & 0.000 & 0.000 & 0.000 & 0.000 & 0.000 & 0.000 & $0.000 * * *$ & $0.000 * * *$ & 0.000 \\
\hline Convenient & $0.000 * * *$ & $=0.000$ & $0.000 * * *$ & $0.000 * * *$ & $0.000 * *$ & 0.000 & 0.000 & $0.000 * * *$ & $0.000 * * *$ & $0.000 * * *$ & 0.000 & 0.000 \\
\hline Club & $0.000 * * *$ & $=0.000 * *$ & 0.000 & 0.000 & 0.000 & $0.000 * * *$ & $0.000 * *$ & $0.000 * * *$ & $0.000 * *$ & $0.000 * * *$ & $0.000 *$ & 0.000 \\
\hline \multicolumn{13}{|l|}{ Household characteristics } \\
\hline Constant & $-0.113 * *$ & $0.090 * *$ & $0.265 * * *$ & $0.029 * *$ & -0.025 & $0.275 * * *$ & -0.015 & $-0.097 * *$ & 0.184 *** & $0.217 * * *$ & $0.190 * * *$ & 0.001 \\
\hline 1/HHSIZE & $0.103 * * *$ & -0.003 & $-0.017 *$ & 0.005 & -0.001 & $-0.035 * * *$ & $0.021 *$ & $-0.038 * * *$ & $-0.032 * * *$ & -0.014 & $-0.018 * * *$ & 0.031 \\
\hline $\ln \left(\mathrm{H} \_\right.$age $)$ & $-0.062 * * *$ & $-0.039 * * *$ & 0.006 & $0.010 * * *$ & $0.015 * * *$ & $-0.026 * * *$ & $0.021 * *$ & $0.106 * * *$ & 0.006 & $0.028 * *$ & $-0.052 * * *$ & -0.014 \\
\hline Boy_6 & -0.005 & $0.014 * *$ & 0.004 & -0.006 & 0.003 & -0.006 & 0.016 & -0.006 & -0.005 & -0.002 & 0.003 & -0.011 \\
\hline Girl_6 & -0.011 & $0.021 * * *$ & $0.019 * *$ & -0.003 & 0.001 & -0.004 & 0.011 & -0.003 & -0.013 & -0.012 & -0.003 & -0.004 \\
\hline Boy_12 & 0.001 & -0.006 & 0.005 & -0.002 & 0.000 & 0.003 & -0.008 & -0.003 & 0.000 & 0.000 & $0.013 * * *$ & -0.003 \\
\hline Girl_12 & 0.001 & $-0.013 * * *$ & $0.016 * * *$ & $-0.004 *$ & 0.001 & 0.002 & -0.001 & -0.008 & -0.005 & 0.009 & $0.009 * * *$ & -0.007 \\
\hline Boy_17 & 0.005 & $-0.010 * *$ & 0.004 & $-0.006 * * *$ & -0.001 & $0.013 * * *$ & -0.008 & -0.006 & -0.001 & -0.004 & $0.018 * * *$ & -0.005 \\
\hline Girl_17 & -0.002 & -0.005 & 0.003 & -0.003 & 0.001 & $0.012 * * *$ & -0.009 & -0.008 & 0.000 & 0.009 & $0.012 * * *$ & -0.009 \\
\hline College & $0.007 *$ & $-0.024 * * *$ & $0.023 * * *$ & $-0.006 * * *$ & 0.001 & $0.008 * * *$ & $0.021 * * *$ & 0.003 & $-0.022 * * *$ & $-0.017 * * *$ & $-0.005 * * *$ & 0.010 \\
\hline H_work & -0.001 & 0.000 & $0.008 * *$ & -0.001 & $-0.005 * * *$ & $0.011 * * *$ & -0.005 & -0.002 & 0.001 & -0.005 & 0.002 & -0.002 \\
\hline Black & $-0.040 * * *$ & $0.015 * * *$ & $-0.024 * * *$ & $0.013 * * *$ & $0.015 * * *$ & $-0.023 * * *$ & $0.071 * * *$ & $-0.047 * * *$ & 0.044 *** & $-0.031 * * *$ & $0.015 * * *$ & -0.007 \\
\hline Hispanic & 0.010 & 0.002 & 0.010 & $0.012 * * *$ & 0.003 & $-0.020 * * *$ & $0.018 *$ & $-0.019 * *$ & -0.013 & -0.014 & 0.006 & 0.007 \\
\hline Othrace & 0.000 & $0.021 * * *$ & $-0.012 * *$ & $0.013 * * *$ & 0.002 & $-0.013 * * *$ & $0.032 * * *$ & $-0.012 * * *$ & $-0.010 *$ & $-0.020 * * *$ & 0.005 & -0.006 \\
\hline Rural & $0.030 * * *$ & $=-0.009$ & $-0.012 *$ & -0.003 & 0.000 & -0.005 & -0.008 & 0.003 & -0.003 & -0.001 & 0.001 & 0.007 \\
\hline Married & $-0.015 * * *$ & $-0.024 * * *$ & $0.015 * * *$ & 0.002 & $0.004 * *$ & $0.005 * *$ & 0.002 & $0.020 * * *$ & 0.006 & $-0.011 *$ & $-0.009 * * *$ & 0.004 \\
\hline East & $-0.022 * * *$ & -0.005 & 0.001 & $-0.003 *$ & $-0.004 * *$ & $0.004 *$ & 0.003 & $0.010 * *$ & $-0.012 * * *$ & $0.028 * * *$ & 0.002 & -0.002 \\
\hline Central & -0.007 & -0.003 & $-0.008 *$ & 0.002 & -0.002 & 0.003 & $-0.016 * * *$ & $-0.009 *$ & $0.021 * * *$ & $0.025 * * *$ & 0.004 & -0.010 \\
\hline West & 0.005 & $0.017 * * *$ & $-0.017 * * *$ & $0.004 * * *$ & -0.001 & 0.001 & $-0.016 * * *$ & -0.004 & $0.022 * * *$ & -0.003 & 0.001 & -0.010 \\
\hline Expenditure & $0.090 * * *$ & $0.024 * * *$ & $-0.048 * * *$ & 0.001 & -0.005 & $-0.033 * * *$ & 0.005 & $-0.042 * * *$ & $-0.021 * * *$ & -0.004 & $0.010 * *$ & 0.021 \\
\hline \multicolumn{13}{|l|}{ Price $^{2}$} \\
\hline Low fat milk & $-0.108 * * *$ & & & & & & & & & & & \\
\hline Whole milk & $0.045 * * *$ & $-0.061 * * *$ & & & & & & & & & & \\
\hline Yogurt & $0.021 * * *$ & $=0.008 *$ & $0.018 * * *$ & & & & & & & & & \\
\hline Eggs & -0.002 & 0.000 & $-0.004 * *$ & $0.035 * * *$ & & & & & & & & \\
\hline Hot cereals & 0.004 & -0.001 & $-0.005 * * *$ & $-0.004 * * *$ & $0.011 * * *$ & & & & & & & \\
\hline Breakfast bar & $0.011 * * *$ & $=0.004$ & $-0.008 * * *$ & -0.001 & 0.001 & $0.011 * * *$ & & & & & & \\
\hline Juice & 0.001 & -0.005 & $0.007 * *$ & -0.002 & 0.000 & -0.002 & $0.008 *$ & & & & & \\
\hline Coffee & $0.026 * * *$ & $0.007 * * *$ & $-0.018 * * *$ & -0.001 & $-0.004 * * *$ & $-0.011 * * *$ & -0.002 & $0.017 * * *$ & & & & \\
\hline Meats & $0.020 * * *$ & $=0.004$ & $-0.012 * * *$ & $-0.004 * * *$ & -0.002 & $-0.005 * *$ & -0.003 & $-0.009 * * *$ & $0.026 * * *$ & & & \\
\hline Breads & $0.027 * * *$ & $0.007 *$ & $-0.008 * *$ & $-0.009 * * *$ & -0.001 & -0.004 & $-0.007 * *$ & $-0.009 * * *$ & $-0.015 * * *$ & $0.012 * * *$ & & \\
\hline Low-nutrition cereals & $-0.012 * * *$ & -0.005 & 0.004 & $-0.004 * * *$ & 0.001 & 0.001 & -0.002 & 0.000 & -0.002 & 0.003 & $0.017 * * *$ & \\
\hline High-nutrition cereals & -0.033 & -0.003 & -0.003 & -0.005 & -0.001 & 0.003 & 0.005 & 0.004 & 0.002 & 0.003 & -0.001 & 0.027 \\
\hline R-squared & 0.107 & 0.096 & 0.060 & 0.150 & 0.029 & 0.051 & 0.053 & 0.180 & 0.080 & 0.039 & 0.121 & 0.041 \\
\hline
\end{tabular}

1. The equation for high-nutrition cereals is dropped in the estimation to avoid singularity. Their parameter estimates are derived using the adding-up and symmetry constraints.

2. The parameter estimates of price variables in the upper off-diagonal matrix can be derived using the symmetry constriant 